\title{
Methionine and Threonine Requirements of Dutch Rabbits Fed under a Cecotrophy Prevention Program
}

\author{
Yumi Abe, Hitoshi Muramatsu, Seizi Sukemori \\ Graduate School of Agriculture, Tokyo University of Agriculture, Atsugi, Japan \\ Email: sukemori@nodai.ac.jp
}

How to cite this paper: Abe, Y., Muramatsu, H. and Sukemori, S. (2019) Methionine and Threonine Requirements of Dutch Rabbits Fed under a Cecotrophy Prevention Program. Open Journal of Animal Sciences, 9, 163-172. https://doi.org/10.4236/ojas.2019.92014

Received: January 10, 2019

Accepted: March 17, 2019

Published: March 20, 2019

Copyright $\odot 2019$ by author(s) and Scientific Research Publishing Inc. This work is licensed under the Creative Commons Attribution International License (CC BY 4.0).

http://creativecommons.org/licenses/by/4.0/

\section{c) (i) Open Access}

\begin{abstract}
It is suggested that the difference in body size between domestic-type rabbits and small pet-type rabbits results in different nutrient requirements. The nutritional requirements of pet rabbits have been assessed, although such assessments require evaluation throughout the rabbit life span. The present study was conducted under a cecotrophy prevention program with young and adult rabbits. Six male Dutch rabbits were housed individually in a dormitory-type cage, and they were randomly fed graded levels of dietary methionine and threonine, at ratios of 4:0, 3:1, 2:2, 1:3, and 0:4 mixed with two types of feed, 4:0 and 0:4. Four days after switching diets and $4 \mathrm{hrs}$ after starting morning feeding, approximately one milliliter of blood was collected from the vein of the ear. Free amino acid concentrations in the plasma were determined with a high-speed amino acid analyzer. Plasma concentrations of methionine and threonine compared to dietary methionine and threonine levels are shown in young rabbits. The plasma concentration of methionine remained constant at a low level and then increased linearly. The intersection was estimated as $0.16 \mathrm{~g} / \mathrm{d}$. In the same manner, the intersection of the plasma threonine value was estimated as $0.27 \mathrm{~g} / \mathrm{d}$. These values were calculated as $0.27 \%$ and $0.47 \%$ of the diets, respectively. In the case of adult rabbits, the baseline was not obtained for dietary methionine and threonine levels. The methionine requirement was estimated as $0.11 \mathrm{~g} / \mathrm{d}$. The threonine requirement was estimated as $0.22 \mathrm{~g} / \mathrm{d}$. These values were calculated as $0.15 \%$ and $0.30 \%$ of the diets, respectively. In comparison with young and adult rabbits, both methionine and threonine showed a low baseline level in young rabbits, while their variations in plasma levels of adult rabbits were not determined. The requirement of both amino acids in young rabbits is higher than that in adult rabbits. The dietary values of both amino acids in young rabbits were also higher than those in adult rabbits. Small pet-type adult rabbits required lower amino acid levels than domestic-type rabbits.
\end{abstract}




\section{Keywords}

Dutch Rabbit, Methionine, Threonine, Requirement, Plasma Level

\section{Introduction}

Detailed information on the nutritional requirements of rabbits has been derived from studies with strains that produce meat and/or fur. Currently, there are more than 50 breeds of rabbits in the world, and feeding objectives do not consider rabbits for production of meat and fur and/or for research. Rabbits, as a pet animal have a very important status in the life of humans. It has been suggested that the difference in body size between the domestic-type rabbits and the small pet-type rabbits causes different nutrient requirements for maintenance [1]. Therefore, assessment of the nutritional requirements of pet rabbits has increased their life span. However, nutritional requirement data for pet rabbits are not sufficient. In this study, the free amino acid levels in the plasma of rabbits fed various dietary amino acid levels were used to determine amino acid requirements. This method has been reported for several animal strains and the authors previously reported the lysine, valine, methionine and threonine requirements of domestic rabbits [2] [3]. Hoover and Heitmann [4] suggested that free amino acids were synthesized with non-protein nitrogen in the digestive tract and were supplied by cecotrophy. Our previous study [5] also showed that rabbits can use amino acids synthesized by microorganisms in their digestive tracts. Moughan et al. [6] proposed that the whole-body amino acid pattern can be used to approximate an ideal balance of dietary amino acids, and their data indicate discrepancies in the recommended essential amino acid requirements for growth in rabbits. Furthermore, in our earlier study [3], it was suggested that methionine and threonine were supplied by cecotrophy of the soft feces produced by cecum microorganisms; therefore, the present study was conducted under a cecotrophy prevention practice with young and adult Dutch rabbits as pet rabbits. In this study, methionine and threonine were chosen, because no report has indicated metabolic interaction between these amino acids.

\section{Materials and Methods}

The present study was conducted with consideration for animal welfare established in the guidelines for animal experiments at Tokyo University of Agriculture.

\subsection{Animals and Feeding Environmental Conditions}

Six male Dutch rabbits weighing $0.71 \pm 0.1 \mathrm{~kg}$ at 5 weeks of age were purchased from Kitayama Rabes Co., Ltd. in Nagano. In this study we could not prepare the female rabbits. They were housed individually in a dormitory-type cage $(32 \times$ $47 \times 35 \mathrm{~cm}$ ) in a room, in which temperature and relative humidity were con- 
trolled at $24^{\circ} \mathrm{C} \pm 1^{\circ} \mathrm{C}$ and $60 \%$, respectively.

\subsection{Diets and Time Schedule of the Study}

After the preliminary feeding of the rabbits with cecotrophy prevention methods utilizing color, the first study with the young stage was conducted at 7 weeks of age for 20 days to observe the amino acid requirements.

The experimental diets contained $14 \%$ of CP (Table 1). Two diets were prepared with methionine $(0.3 \%)$ and threonine $(0.3 \%)$. Methionine: threonine was 4:0 and 0:4 (Table 2). To formulate the graded levels of dietary methionine and

Table 1. Ingredients and chemical composition of the experimental diets (\%).

\begin{tabular}{|c|c|c|c|}
\hline & 1 & & 2 \\
\hline Wheat flour & & 10.0 & \\
\hline Soybean meal & & 11.9 & \\
\hline Alfalfa meal & & 8.0 & \\
\hline Millet meal & & 36.0 & \\
\hline Corn starch & & 28.0 & \\
\hline Soybean oil & & 0.5 & \\
\hline Beer yeast & & 2.0 & \\
\hline $\mathrm{NaCl}$ & & 0.5 & \\
\hline $\mathrm{CaCO}_{3}$ & & 0.5 & \\
\hline $\mathrm{Ca}_{3}\left(\mathrm{PO}_{4}\right)_{2}$ & & 0.1 & \\
\hline Pre $\operatorname{mix}^{1)}$ & & 0.2 & \\
\hline Amino acid mix. ${ }^{2)}$ & & 2.0 & \\
\hline L-Met & 0.3 & & - \\
\hline L-Thr & - & & 0.3 \\
\hline \multicolumn{4}{|l|}{ Chemical analysis } \\
\hline Moisture & & 9.6 & \\
\hline $\mathrm{CP}$ & & 13.6 & \\
\hline Ether extracts & & 1.65 & \\
\hline Crude fiber & & 56.6 & \\
\hline NFE & & 13.0 & \\
\hline Crude ash & & 5.56 & \\
\hline GE (kcal/g) & & 3.94 & \\
\hline
\end{tabular}

${ }^{1)}$ Contains vitamin $\mathrm{A}, \mathrm{D}, \mathrm{E}, \mathrm{B}_{1}, \mathrm{~B}_{2}, \mathrm{~B}_{6}, \mathrm{~B}_{12}, \mathrm{C}$, niacin, pantothenic acid, biotin, folic acid, choline chloride, inositol, $\mathrm{FeSO}_{4}, \mathrm{MnSO}_{4}, \mathrm{CoSO}_{4}$, and $\mathrm{KIO}_{3} .{ }^{2}$ Contains essential amino acids (leucine, lysine, arginine, phenylalanine, isoleucine, histidine, tryptophan and valine) and glutamic acid.

Table 2. Dietary level of methionine and threonine (\%).

\begin{tabular}{cccccc}
\hline Mix ratio of Met:Thr & $4: 0$ & $3: 1$ & $2: 2$ & $1: 3$ & $0: 4$ \\
\hline Met & 0.44 & 0.36 & 0.29 & 0.22 & 0.14 \\
Thr & 0.38 & 0.46 & 0.53 & 0.60 & 0.68 \\
\hline
\end{tabular}


threonine, the two prepared diets were mixed at ratios of 4:0, 3:1, 2:2, 1:3, and $0: 4$. The diet was administered using a time-controlled feeding method for $1 \mathrm{hr}$ (9:00 - 10:00) and $3 \mathrm{hrs}(16: 00-19: 00)$ in a day. The rabbits were fed ad libitum. Each experimental diet was provided for 4 days in the following order: 1, 4, 2, 5, 3. It was recognized that the plasma free amino acid concentration responded to the new amino acid dietary levels by 3 days after the dietary changes. In addition, the changes in dietary amino acid levels were reflected in the plasma amino acid levels within $2 \mathrm{hr}$ after eating began. Therefore, in the fourth day after switching diets and $4 \mathrm{hr}$ after starting morning feeding, approximately one $\mathrm{mL}$ of blood was collected from the vein of the ear. Body weight was determined before switching diets, and diet intake was recorded everyday.

\subsection{Sample Preparation}

Collected blood was centrifuged at $6.93 \mathrm{~g}$ for $5 \mathrm{~min}$, and plasma was obtained. This plasma was thoroughly mixed with the same volume of $8 \%$ sulfosalicylic acid solution. After $10 \mathrm{~min}$ of decantation, the mixture was centrifuged at $6.93 \mathrm{~g}$ for $5 \mathrm{~min}$ under $5^{\circ} \mathrm{C}$. Supernatant fluid was filtered with a $0.45 \mu \mathrm{m}$ filter (Advantec, Dismic-25) as reported previously [2] [3] and kept in a $-40^{\circ} \mathrm{C}$ freezer until the determination of free amino acids.

After the first study, the rabbits were fed a commercial diet until they grew up to the adult stage at 35 weeks of age. The second study was conducted with 35-weeks-old rabbits in the same manner as the first study.

Free amino acid concentrations in the plasma kept at $-40^{\circ} \mathrm{C}$ were determined with a high-speed amino acid analyzer (Hitachi L-8500).

\subsection{Statistical Treatment}

Statistical treatment was carried out by one-way analysis of variance. When a significant difference $(\mathrm{P}<0.05)$ was recognized, the means were analyzed by Tukey's multiple range test. The requirements of methionine and threonine were estimated by the broken line model.

\section{Results and Discussion}

Body weight gain and feed efficiency decreased in proportion to a decrease in methionine intake, and there was no change induced by a decrease in threonine intake, as shown in both stages in Table 3. Diet intake showed the maximum values in the methionine:threonine 2:2 groups and decreased in accordance with both amino acid levels. Spreadbury [7] reported that the decrease in methionine and cystine levels in the diet reduced body weight gain and feed intake in a study with New Zealand White rabbits, and the present data agreed with these findings. Taboada et al. [8] reported that there were no significant effects of methionine and cysteine levels on body weight gain and feed intake in their study with cross-bred rabbits. Colin and Ghezal-Triki [9] reported that the dietary threonine level slightly affects the feed intake $(P=0.056-0.096)$ and daily weight gain 
Table 3. Body weight gain, diet intake and feed efficiency.

\begin{tabular}{cccccc}
\hline \multicolumn{1}{c}{ Diet group } & $4: 0$ & $3: 1$ & $2: 2$ & $1: 3$ & $0: 4$ \\
\hline Young rabbit & & & & & \\
Body weight gain (g/day) & $10.7 \pm 1.9^{\mathrm{b}}$ & $18.1 \pm 2.6^{\mathrm{a}}$ & $17.3 \pm 2.4^{\mathrm{a}}$ & $8.3 \pm 2.2^{\mathrm{b}}$ & $8.5 \pm 1.4^{\mathrm{b}}$ \\
Diet intake (g/day) & $47.3 \pm 1.8^{\mathrm{c}}$ & $59.3 \pm 2.3^{\mathrm{b}}$ & $66.1 \pm 2.7^{\mathrm{a}}$ & $48.1 \pm 3.1^{\mathrm{c}}$ & $55.1 \pm 0.9^{\mathrm{b}}$ \\
Feed efficiency (\%) & $22.4 \pm 3.6^{\mathrm{ab}}$ & $30.5 \pm 4.3^{\mathrm{a}}$ & $25.7 \pm 3.2^{\mathrm{a}}$ & $16.2 \pm 3.4^{\mathrm{b}}$ & $15.4 \pm 2.4^{\mathrm{b}}$ \\
Adult rabbit & & & & & \\
Body weight gain (g/day) & $1.5 \pm 6.0^{\mathrm{ab}}$ & $4.0 \pm 2.1^{\mathrm{ab}}$ & $7.1 \pm 1.4^{\mathrm{a}}$ & $-1.6 \pm 4.3^{\mathrm{ab}}$ & $-6.0 \pm 2.5^{\mathrm{b}}$ \\
Diet intake (g/day) & $69.6 \pm 2.3$ & $70.9 \pm 1.9$ & $74.0 \pm 2.7$ & $71.2 \pm 2.3$ & $69.3 \pm 4.9^{2.9}$ \\
Feed efficiency (\%) & $2.8 \pm 9.5^{\mathrm{ab}}$ & $5.5 \pm 2.8^{\mathrm{ab}}$ & $9.5 \pm 1.8^{\mathrm{a}}$ & $-2.6 \pm 6.3^{\mathrm{ab}}$ & $-10.1 \pm 5.2^{\mathrm{b}}$ \\
\hline
\end{tabular}

Each value is means for 6 rabbits. ${ }^{\mathrm{a}-\mathrm{c}}$ means with different superscripts in the same row are significantly different $(\mathrm{P}<0.05)$.

$(P=0.047-0.032)$ with a quadratic effect among the tested threonine levels; the present data showed the same trend.

In the statistical treatment of plasma amino acid concentration (Table 4), serine, alanine, cysteine, and tyrosine without threonine and methionine showed a significant difference under the unstable tendency in young rabbits. Serine, glutamate, glycine, valine without threonine and methionine also showed significant differences under the unstable tendency in adult rabbits (Table 5). The plasma concentrations of methionine and threonine clearly changed in accordance with the dietary supply levels, except for the stable level of methionine in young rabbits fed a low-methionine diet. Cystine and cysteine can replace 50\% of the methionine requirement, but their increase in accordance with the deletion of dietary methionine was not recognized in the previous study [3], and the same trend was also obtained in this study. Therefore, the present results showed the simple methionine requirement. On the other hand, all amino acids except the abovementioned amino acids were not affected by dietary methionine and/or threonine levels, although they showed fractional variation in their levels. The abovementioned amino acids showed significant differences and were also not affected directly by the change in the level of threonine and/or methionine, because their variation was not parallel to it of threonine and/or methionine. It has already been reported that when a given amino acid level is less than required, its plasma concentration remains constant at a relatively low level (baseline), as shown in the variation of methionine of young rabbits [2] [3]. When the dietary level of tested amino acids exceeds the requirement, the plasma concentration increases linearly with increasing dietary levels (linear line). The intersection of both lines predicts the requirement of tested amino acid. In Figure 1 and Figure 2, plasma concentrations of methionine and threonine against dietary methionine and threonine levels are shown in young rabbits. The plasma concentration of methionine remained constant at a low level (under $0.15 \mathrm{~g} /$ day intake) and then increased linearly. In our previous study, dietary essential amino acid level is less than the requirement, its level remains constant at relatively low level and 
Table 4. Plasma free amino acid concentrations of young rabbits ( $\mathrm{nmol} / \mathrm{ml})$.

\begin{tabular}{cccccccc}
\hline & \multicolumn{5}{c}{ Diet group (Met:Thr) } & \multicolumn{3}{c}{ Pooled } & \\
\hline Amino acid & $4: 0$ & $3: 1$ & $2: 2$ & $1: 3$ & $0: 4$ & SD & \\
\hline Tau & 68 & 48 & 45 & 41 & 67 & 19 & NS \\
Asp* & 7 & - & 10 & 7 & 13 & & \\
Thr & $37^{\mathrm{d}}$ & $71^{\mathrm{cd}}$ & $91^{\mathrm{bc}}$ & $125^{\mathrm{b}}$ & $191^{\mathrm{a}}$ & 55 & \\
Ser & $189^{\mathrm{b}}$ & $218^{\mathrm{ab}}$ & $187^{\mathrm{b}}$ & $208^{\mathrm{ab}}$ & $278^{\mathrm{a}}$ & 52 & \\
Glu & 47 & 57 & 36 & 46 & 53 & 13 & NS \\
Gly & 692 & 695 & 759 & 772 & 896 & 165 & NS \\
Ala & $704^{\mathrm{b}}$ & $1116^{\mathrm{a}}$ & $1106^{\mathrm{a}}$ & $821^{\mathrm{ab}}$ & $975^{\mathrm{ab}}$ & 213 & \\
Cys & $21^{\mathrm{ab}}$ & $24^{\mathrm{a}}$ & $23^{\mathrm{ab}}$ & $15^{\mathrm{ab}}$ & $13^{\mathrm{b}}$ & 7 & \\
Val & 115 & 149 & 146 & 129 & 174 & 41 & NS \\
Met & $113^{\mathrm{a}}$ & $107^{\mathrm{a}}$ & $69^{\mathrm{b}}$ & $11^{\mathrm{c}}$ & $13^{\mathrm{c}}$ & 45 & \\
Ile & 101 & 133 & 130 & 118 & 115 & 38 & NS \\
Leu & 67 & 97 & 86 & 72 & 110 & 29 & NS \\
Tyr & $45^{\mathrm{b}}$ & $65^{\mathrm{ab}}$ & $61^{\mathrm{b}}$ & $41^{\mathrm{b}}$ & $92^{\mathrm{a}}$ & 23 & \\
Phe & 35 & 47 & 38 & 27 & 45 & 13 & NS \\
Lys & 157 & 197 & 210 & 173 & 222 & 69 & NS \\
His & 77 & 84 & 85 & 61 & 107 & 27 & NS \\
Arg & 159 & 180 & 175 & 108 & 176 & 45 & NS \\
Pro & 277 & 371 & 356 & 309 & 388 & 78 & NS \\
\hline
\end{tabular}

*: Statistical analysis could not be conducted because of value deletions.

Table 5. Plasma free amino acid concentrations of adult rabbits (nmol/ml).

\begin{tabular}{cccccccc}
\hline & \multicolumn{3}{c}{ Diet group } & \multicolumn{3}{c}{ Pooled } & \\
\hline Amino acid & $4: 0$ & $3: 1$ & $2: 2$ & $1: 3$ & $0: 4$ & SD & \\
\hline Tau & 50 & 51 & 47 & 39 & 49 & 12 & NS \\
Asp* & - & - & - & - & - & & \\
Thr & $85^{\mathrm{c}}$ & $123^{\mathrm{bc}}$ & $135^{\mathrm{ab}}$ & $177^{\mathrm{a}}$ & $173^{\mathrm{a}}$ & 38 & \\
Ser & $217^{\mathrm{b}}$ & $218^{\mathrm{b}}$ & $229^{\mathrm{ab}}$ & $265^{\mathrm{a}}$ & $245^{\mathrm{ab}}$ & 25 & \\
Glu & $51^{\mathrm{ab}}$ & $41^{\mathrm{b}}$ & $48^{\mathrm{ab}}$ & $58^{\mathrm{a}}$ & $47^{\mathrm{ab}}$ & 8 & \\
Gly & $624^{\mathrm{c}}$ & $638^{\mathrm{c}}$ & $783^{\mathrm{bc}}$ & $806^{\mathrm{a}}$ & $794^{\mathrm{a}}$ & 111 & \\
Ala & 607 & 674 & 606 & 663 & 607 & 82 & NS \\
Cys & 54 & 53 & 46 & 55 & 51 & 19 & NS \\
Val & $150^{\mathrm{b}}$ & $164^{\mathrm{ab}}$ & $158^{\mathrm{ab}}$ & $179^{\mathrm{a}}$ & $159^{\mathrm{ab}}$ & 14 & \\
Met & $100^{\mathrm{a}}$ & $76^{\mathrm{b}}$ & $66^{\mathrm{b}}$ & $43^{\mathrm{c}}$ & $21^{\mathrm{d}}$ & 27 & \\
Ile & 78 & 84 & 96 & 101 & 88 & 16 & NS \\
Leu & 116 & 116 & 112 & 126 & 116 & 20 & NS \\
\hline
\end{tabular}




\section{Continued}

\begin{tabular}{cccccccc}
\hline Tyr & 97 & 87 & 89 & 98 & 96 & 17 & NS \\
Phe & 57 & 54 & 52 & 59 & 55 & 8 & NS \\
Lys & 157 & 158 & 165 & 178 & 165 & 13 & NS \\
His & 89 & 82 & 83 & 86 & 89 & 8 & NS \\
3-Mehis & 9 & 7 & 9 & 9 & 9 & 2 & NS \\
Arg & 141 & 121 & 154 & 144 & 133 & 30 & NS \\
Pro & 226 & 245 & 258 & 272 & 245 & 27 & NS
\end{tabular}

*: Aspartic acid was not detected in the serum from adult rabbits.

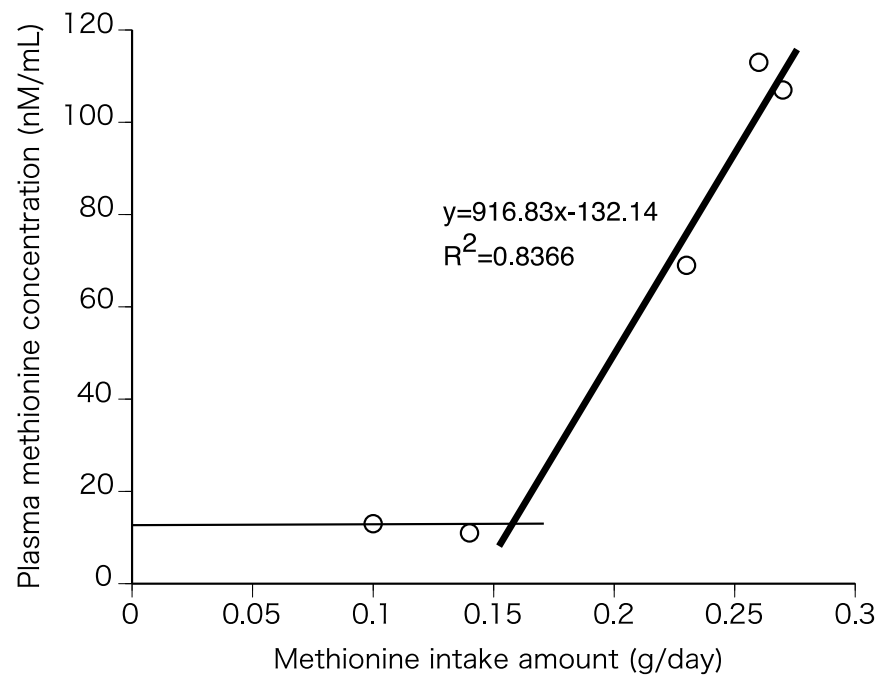

Figure 1. Relationship of methionine intake amount and plasma methionine concentration in young rabbits. Values used are the means of 6 rabbits.

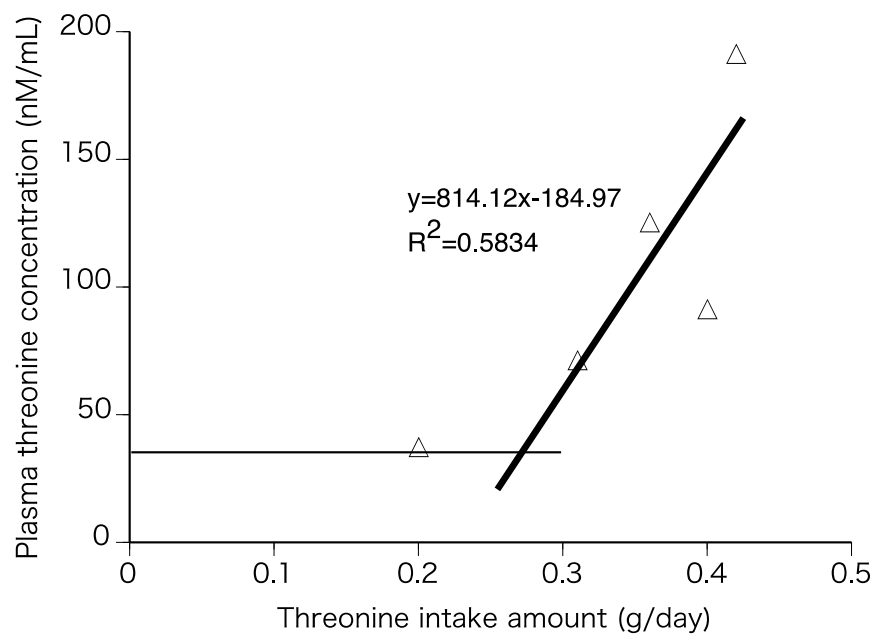

Figure 2. Relationship of threonine intake amount and plasma threonine concentration in young rabbits. Values used are the means of 6 rabbits.

the dietary level of it exceeds the requirement, the level of it increases linearly with increasing dietary levels. Therefore, the intersection level means a require- 
ment level. The current intersection of methionine was estimated as $0.16 \mathrm{~g} / \mathrm{d}$. In the same manner, the intersection of plasma threonine value was estimated as $0.27 \mathrm{~g} / \mathrm{d}$. These values were calculated as $0.27 \%$ and $0.47 \%$ of the diets.

In Figure 3 and Figure 4, plasma concentrations of methionine and threonine against dietary amino acid supply levels are shown in adult rabbits. In the case of adult rabbits, the baseline was not obtained from dietary methionine and threonine levels. The methionine requirement was estimated as $0.11 \mathrm{~g} / \mathrm{d}$. The threonine requirement was estimated as $0.22 \mathrm{~g} / \mathrm{d}$. These values were calculated as $0.15 \%$ and $0.30 \%$ of the diets.

In a previous study [3] of adult Japanese white rabbits, the methionine and threonine requirement values were $0.23 \mathrm{~g} / \mathrm{d}$ and $0.42 \mathrm{~g} / \mathrm{d}$, and their dietary ingredients were $0.28 \%$ and $0.52 \%$ of the diets, respectively. The requirements of both amino acids by young rabbits in this study were approximate values. With

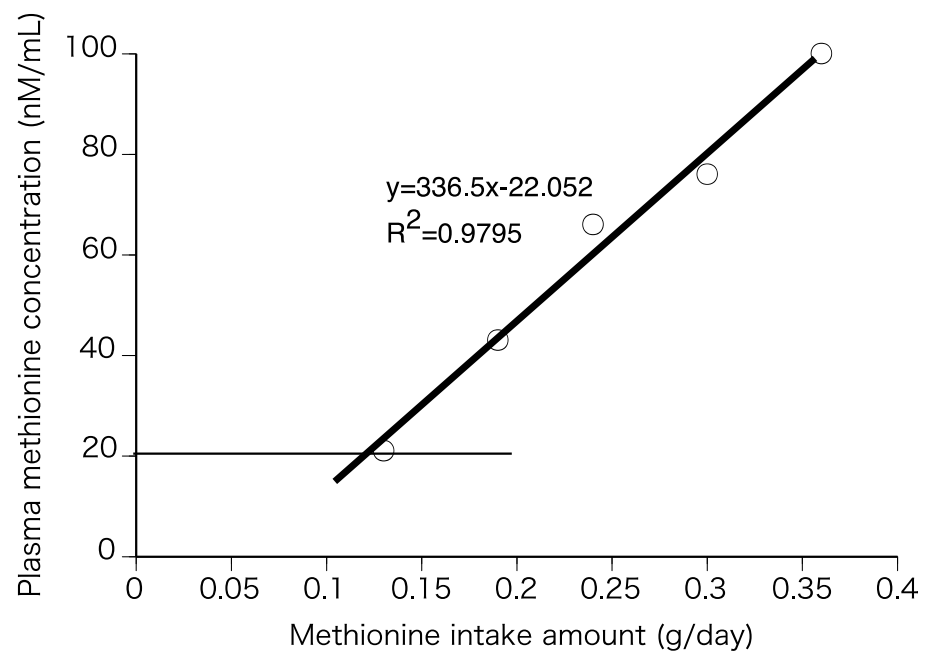

Figure 3. Relationship of methionine intake amount and plasma methionine concentration in adult rabbits. Values used are the means of 6 rabbits.

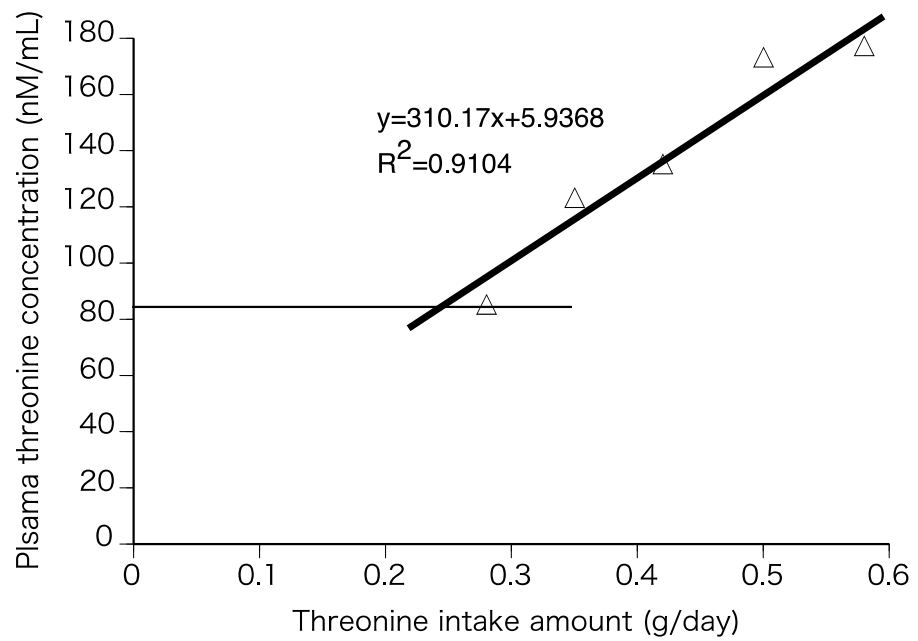

Figure 4. Relationship of threonine intake amount and plasma threonine concentration in adult rabbits. Values used are the means of 6 rabbits. 
our data suggesting a methionine requirement of $0.28 \%$ of the diet [3] and the present data suggesting that of $0.27 \%$, it seems that the methionine requirement is not as large as claimed in comparison with the earlier reports [7] [8] [10] [11] [12] which proposed methionine requirements at $0.45 \%-0.62 \%$ of the diet; this range could be affected by the unknown cysteine levels. On the other hand, the requirement level of threonine in earlier studies [9] [10] [12] [13] [14] was $0.50 \%$ - $0.64 \%$ of the diet. Therefore, the level of threonine required by young animals, i.e., the active growth stage of small pet-type rabbits, does not differ from the requirement level of domestic-type rabbits.

The present data of both amino acids from adult Dutch rabbits are half the values of previous data [3]. In this study, the plasma concentration of methionine showed a constant low level as a baseline, but the plasma concentration of threonine did not show a constant low level, i.e., the minimum supply from the present diet was sufficient for the requirement of adult Dutch rabbits. The diet used was the same as that used in the previous study. In a previous study [3], the plasma concentration of both amino acids showed a constant low level, i.e., the minimum supply from the diet was insufficient for the requirement of adult Dutch rabbits. Therefore, small pet-type rabbits required lower amino acid values than do domestic-type rabbits.

In comparison with young and adult rabbits in the present study, both methionine and threonine showed a low baseline level in young rabbits, while their variations in plasma levels of adult rabbits was not determined. Furthermore, the requirement of both amino acids in young rabbits is higher than that in adult rabbits. The dietary values of both amino acids in young rabbits were also higher than those in adult rabbits. Maertens et al. [15] proposed that protein and amino acid requirements decrease with increasing age, and our data agree with their proposal.

\section{Acknowledgements}

The authors wish to thank Mr. T. Sakoda, and Mr. H. Goto, for the determination of amino acids and Ms. S. Hashimoto and Ms. Y. Umehara for their help in the maintenance of rabbits, preparation of samples, and statistical analysis of data in this study.

\section{Conflicts of Interest}

The authors declare no conflicts of interest regarding the publication of this paper.

\section{References}

[1] Lowe, J.A. (1998) Pet Rabbit Feeding and Nutrition. In: de Blas, J.C. and Wiseman, J., Eds., The Nutrition of the Rabbit, CABI Publishing, London, UK.

[2] Muramatsu, H., Erikawa, T., Takeishi, M., Takahashi, Y., Kurosawa, A., Ikeda, S., Shibui, H. and Sukemori, S. (2008) Response of Plasma Free Lysine and Valine Concentrations of Growing Rabbits to Dietary Changes in Both Amino Acid Levels. 
Journal of Pet Animal Nutrition, 11, 61-66.

[3] Abe, Y., Sakoda, T., Goto, H., Ikeda, S. and Sukemori, S. (2014) Cecotrophy Contribute Methionine and Threonine Requirements of Rabbits. Journal of Pet Animal Nutrition, 17, 6-12.

[4] Hoover, W.H. and Heitmann, R.N. (1975) Cecal Nitrogen Metabolism and Amino Acid Absorption in the Rabbit. Journal of Nutrition, 105, 245-252. https://doi.org/10.1093/jn/105.2.245

[5] Sukemori, S. and Odo, S. (2017) L-Carnitine Contents in the Tissues of Rabbits Feed Urea as an Alternative of Dietary Protein. Open Journal of Animal Science, 7, 1-7. https://doi.org/10.4236/ojas.2017.71001

[6] Moughan, P.J., Schltze, W.H. and Smith, W.C. (1988) Amino Acid Requirements of the Growing Meat Rabbit 1. The Amino Acid Composition of Rabbit Whole-Body Tissue-A Theoretical Estimate of Ideal Amino Acid Balance. Animal Science, 47, 297-301.

[7] Spreadbury, D. (1978) A Study of the Protein and Amino Acid Requirements of the Growing New Zealand White Rabbits with Emphasis on Lysine and the Sulphur-Containing Amino Acids. British Journal of Nutrition, 39, 601-613. https://doi.org/10.1079/BJN19780075

[8] Taboada, E., Mendez, J. and de Blas, J.C. (1996) The Response of Highly Productive Rabbits to Dietary Sulphuramino Acid Content for Reproduction and Growth. Reproduction Nutrition Development, 36, 191-203.

https://doi.org/10.1051/rnd:19960204

[9] Colin, M. and Ghezal-Triki, N. (2001) Threonine: An Essential Amino Acid Not Frequently Used Till Now in Rabbit Feeds Formulation. A Review. World Rabbit Science, 9, 109-115.

[10] Fisher, H. (1976) Protein and Amino Acid Requirements of the Laboratory Rabbit. Laboratory Animal Science, 26, 659-663.

[11] Monteiro-Motta, A.C., Scapinello, C., Oliveira, A.F.G., Figueira, J.L., Catelan, F., Sato, J. and Stanquevis, C.E. (2013) Levels of Lysine and Methionine + Cysteine for Growing New Zealand White Rabbits. Revista Brasileira de Zootecnia, 42.

[12] Adamson, I. and Fisher, H. (1973) Amino Acid Requirement of the Growing Rabbit: An Estimate of Quantitative Needs. Journal of Nutrition, 103, 1306-1310. https://doi.org/10.1093/jn/103.9.1306

[13] Briens, C. (1996) Threonine Requirement of Growing Rabbits. $6^{\text {th }}$ World Rabbit Congress, 1, 117-120. https://doi.org/10.1016/S0377-8401(97)00063-1

[14] de Blas, J.C., Tboada, E., Nicodemus, N., Campos, R., Piquer, J. and Mendez, J. (1998) Performance Response of Lactating and Growing Rabbits to Dietary Threonine Content. Animal Feed Science Technology, 70, 151-160.

[15] Maertens, L., Luzi, F. and De Groote, G. (1997) Effect of Dietary Protein and Amino Acids on the Performance, Carcass Composition and N-Excretion of Growing Rabbits. Annales deZootechnie, 46, 255-268. 